\title{
Research on Internet Financial Services for Rural Economic Development in Jilin Province
}

\author{
Liuyang Zhao ${ }^{1, a}$ \\ ${ }^{1}$ Changchun University of Finance and Economics, Changchun, 130122, China
}

\begin{abstract}
Keywords: Internet Financial Services, Rural Economic Development, Jilin Province
\end{abstract}
\begin{abstract}
In today's comprehensive economic development and development of a well-off society, farmers also need funds to improve rural areas to build their own material and cultural life. On the basis of the lack of collateral or low value in Chinese rural areas, the traditional financial institutions have been in a state of insufficient supply of rural funds. The rise of Internet finance, to solve the rural capital needs and sales of agricultural products put forward a new path selection, the extensive use of P2P platform to the capital idle and shortage of funds to establish a bridge, e-commerce platform to help promote and sell high-quality agricultural products. Based on the analysis of the feasibility of Internet financial services in the rural areas of Jilin Province, this paper hopes to put forward the suggestions to improve the rural financial services in Jilin Province and promote the development of rural economy.
\end{abstract}

\section{Introduction}

Internet finance is the organic combination of Internet technology and financial function, relying on large data and cloud computing in the open Internet platform to form a functional financial format and its service system, including the network platform based on the financial market system, financial services system, financial organizations System, financial products system and the Internet financial regulatory system, and has all the financial, P2P network loan, third party payment, digital money, large data finance, information financial institutions and other financial models. Chinese Internet financial development can be divided into three stages of development: the first stage is the 1990s from the 1990s to the traditional financial industry, the Internet stage; the second stage is 2005 - 2011 before and after the third party to pay a vigorous development stage; And the third stage is since 2011, the Internet substantive financial business development stage. In the process of Internet financial development, the domestic Internet finance presents a variety of business models and operational mechanisms. This paper focuses on the Internet financial model, such as crowds, P2P loan and third party payment, to explore the dynamic analysis of rural economic development.

China is currently in rural areas to the urbanization of the important stage of transition to determine whether a region to achieve urban standards, an important indicator of population indicators and economic indicators from two aspects, and these two indicators are related to rural economic development and farmers are closely related. According to the Development and Reform Commission reported that Chinese urbanization in 2015 reached 56.1\%, compared with the National Bureau of Statistics in 2014 announced 49.7\% increase of 6.4\%, urban population increased to 87.55 million people, from this data can be indirectly seen in rural areas of Chinese economic development fast. Regional economic development is inseparable from the support of funds and the increase in income in rural areas has been in the case of financial difficulties and lack of supply of funds, the Internet financial platform will undoubtedly solve the financial needs of rural areas to facilitate the rapid development of e-commerce and third-party payment the platform also provides a favorable channel for farmers to increase their income.

Many scholars have been concerned about the opportunities offered by Internet finance to rural economic or agricultural development. Fan Lin and Wang Huai-ming (2015) analyzed the financing difficulties of small and medium-sized agricultural enterprises in agriculture, analyzed the financing channels in rural areas with high financing risk and high financing cost. Asset shortage and other status quo, that the Internet finance to provide large data based on micro-credit, point-to-point 
financing, public financing and other models to meet the diverse needs of agricultural small and medium enterprises. Jiang Weiguo and Li Liqing (2015) through the analysis of Chinese new agricultural management of the main financing model innovation, indicating that the Internet financial expansion of new supply channels, with the new agricultural management of the main financing model has a fit, put forward should optimize the Internet financial financing soft environment recommendations. Li Guoying (2015) through the study of "Internet + " and the relationship between modern agricultural industry chain and business model, the Internet will transform the modern agricultural development and improve agricultural production efficiency, agricultural products and rural consumer goods to accelerate the modern agricultural industry and the Internet integration. It can be seen that the related scholars have studied the relationship between Internet finance and rural development from two aspects. First, the Internet financial model provides a new channel for the rural capital demand. First, the Internet platform provides the driving force for the modern agriculture industry. These two aspects analyze the impact of the Internet financial model on the economic development of rural areas.

\section{Analysis of the Necessity of Rural Internet Finance in Jilin Province}

Chinese rural areas to meet the needs of capital resources generally derived from the accumulation of their own wealth, that is, this year's agricultural production investment from previous years, agricultural production income, the funds to meet the daily needs of farmers and agricultural enterprises, such funds recycling model is the endogenous financing model, the biggest drawback of endogenous financing is to affect the expansion of reproduction. With the development of science and technology and technological progress, the modern agricultural industry put forward higher demands on the quality and efficiency of agricultural production. This is a challenge to the traditional agricultural production mode, which requires farmers to change the traditional production mode that relies only on manual operation and introduce more advanced Production equipment and technology, capital problems have become obstacles to the development of modern agricultural industry. Chinese banks and other financial institutions on the farmers and agricultural enterprises, the number of loans less, mainly due to agricultural production by natural factors, the protection of farmers repayment is the sales of agricultural products, if encountered in the year of climate disasters and accidents, farmers can not the possibility of repayment on schedule is very large. The second is the fear of collateral assets. For the peasant individual, the land public system basically determines its lack of collateral; the value of the plant and equipment of the agricultural enterprise is relatively low, the amount of the borrowing funds is insignificant; the traditional bank lending channels are harsh for the farmers and the agricultural enterprises, the Internet financial platform the provision of all-round, point-to-point lending has expanded the funding of rural areas.

\section{Jilin Province Rural Internet Financial Model Analysis}

It is a relatively new venture investment representative. The source of funds is no longer limited to traditional financial institutions such as banks and funds. Private capital has become the main source of small and medium-sized enterprises (SMEs) through the Internet platform to raise funds to the public. With a focus on creativity, low barriers to entry, easy to operate and other characteristics. Peer-to-peer financing is a popular P2P (peer to peer) network credit model, which is a useful complement and perfect for the existing banking system, which avoids the problem that the traditional financial system discriminates the small and medium-sized enterprises when choosing the loan beneficiaries.

By playing the technical advantages of the Internet, Internet finance for agricultural SMEs to provide a more equal, low threshold, convenient financing platform. On the network platform, small and medium-sized agricultural enterprises can obtain the necessary development funds on an equal basis by completing the registration. From the point-to-point financing model, the responsibility of the Internet financial enterprises is to review each loan application, in the applicant's management level, operating efficiency and other aspects of the study after the loan. For the co-ordination model, 
the owner of the money is also through the Internet financial companies to provide a network platform for their own more interested in projects and ideas to invest in social idle funds together. Through the above analysis we can see that no matter what kind of Internet financial platform can effectively help the credit is good, there are planning farmers and agricultural enterprises to obtain the necessary funds to meet the development of modern agricultural industry and the construction of modern rural lay the foundation.

Internet finance in addition to meet the needs of farmers in the modern agricultural industry chain also plays an important role. From the source of agricultural production sources of production, to the production of finished agricultural products sales, Internet financial third-party payment model - that is, e-commerce platform for the circulation of agricultural products to bring great support. Traditional agricultural product sales model is the farmers or agricultural enterprises to produce their own products shipped to the farmers market, or directly sold to wholesalers or retailers and they can earn very little profits, brokers to get the product to the market to obtain high prices a lot of profit. The application of e-commerce platform, so that farmers can sell agricultural products directly to consumers, no middlemen in which the exploitation of profits, farmers can get direct sales income, consumers can get more inexpensive agricultural products. From the current public use of a wide range of e-commerce platform, more and more electricity business platform began selling agricultural products. From the beginning to be involved in agricultural products Taobao, No. 1 shop, to the transformation of agricultural products to increase sales Jingdong Mall, Dangdang, Amazon, including supermarkets, such as supermarkets, such as supermarkets, such as the supermarket network, home appliances Suning Tesco And the United States and other online began to involve agricultural products.

\section{Suggestion of the Internet Finance Service for the Rural Economic Development in Jilin Province}

Develop Jilin Province "Internet + Agriculture" Development Strategy Planning from the Government Level. The government from the management level of unified planning, development of development strategies, so as to promote the "Internet + agriculture" development. First of all, to develop a favorable "Internet + agriculture" policy planning, from the government support + tax relief + financial institutions, such as financing to promote its development. Through the construction of rural information network platform and service center, and actively promote the industrialization of agricultural products in the field of circulation, the establishment of rural data application center, the various types of agricultural information summary and development. The second is to promote the rural areas of Jilin Province, the construction of Internet infrastructure, which is "Internet + agriculture" development of the premise and foundation. We must speed up the development of low-cost intelligent terminal for rural use of the machine, the third is to focus on a group of computer knowledge + knowledge and understand the marketing management of talent, farmers have a plan Training, so that the city in the technical control of the Internet at the same time, in the ideological identity of the "Internet + agriculture", the "Internet + agriculture" to create a national economy to promote sustainable and efficient + stable and stable development of the new engine.

Deeply Integrate Industrial Chain and Innovative Rural Internet Development Model. Traditional marketing model sales side is relatively narrow, high cost of sales, brand awareness has also been limited, although the agricultural products are good, but because of decentralized business to bring the brand advantage is not prominent. At present, the arrival of mobile Internet era is profoundly changing the agricultural production, sales, service, capital and other industrial environment, set the agricultural e-commerce + high-quality green food origin of direct supply, experiential tourism is one of the modern agricultural industry model will give agriculture to bring new opportunities for development, resulting in rural leisure travel, experience, accommodation, product sales and other complex new format. "Internet + agriculture" is the realization of the agricultural industry by leaps and bounds, no longer just a simple Internet access to agriculture, or agricultural integration of the Internet, in order to achieve the middle, to improve the efficiency of 
the old model, but the Internet and the community capital into the track of agricultural development. On the one hand, "Internet + Agriculture" promote specialized division of labor, improve the degree of organization, reduce transaction costs, optimize the allocation of resources and improve labor productivity. On the other hand," Internet + agriculture "through convenience, real-time, Joint, intelligent and other means for the farmland to do, agricultural extension, rural finance, rural management, etc. to provide accurate, dynamic, scientific all-round information services, is becoming a modern agriculture leap-forward development of the new engine.

Innovative Agriculture New Media Marketing Model, Strengthen the Internet + Agriculture Brand Building With the development of science and technology and the development of Internet technology, the traditional marketing model has been gradually to the network, mobile phones, computers, micro-blogging, We-Chat as the carrier, etc. This new media marketing, breaking the traditional agricultural sales information transmission slow, poor communication model, highlighting the new media convenient and convenient, rapid marketing advantages, is the future trend of agricultural development, the future of agricultural business opportunities in this. Strengthen the brand building of agricultural products, but also an important marketing model of Internet \& agriculture. Consumers of the new era more and more attention to brand effect, especially young Internet consumers, the role of brand marketing in more and more can not be ignored. Jilin Province, now the construction of agricultural products brand than other products there is a certain gap, the same brand than other brands of development opportunities, so the future brand of agricultural products will have a broader market space.

\section{Conclusion}

With the popularization of rural Internet finance and the effective integration of traditional risk control and Internet risk control, risk control is the core link in this process. We should control the risk of financial financing and third-party payment of credit risk, and vigorously improve the Internet financial technology platform to promote the sustainable development of rural areas.

\section{Acknowledgements}

Fund Project: The stage results of Jilin Province Education Department scientific research qualification project "Research on Internet finance services for the rural economic development in Jilin Province" Kyrgyz language teaching text [2016] No. 558.

\section{References}

[1] Huang Tianen. Rural financing needs, constraints and rural financial development research [J]. Shopping modernization. 2010 (08)

[2] Yan Hua.Study on Rural Financial Reform Based on Financial Constraints Analysis [J]. Journal of Shaanxi Vocational and Technical College 2009 (02)

[3] Wu Xiaoling. Establishment of modern rural financial system to promote rural financial development[J]. Rural Work Newsletter. 2009 (01)

[4] Liu Zuoxiang. Farmers' reverse elimination, demand-type financial suppression and rural financial development in China [J] .Analysis of economic problems. 2007 (04)

[5] He Weijiang. Analysis of Chinese rural financial deepening of the policy orientation[J]. Shanghai Finance. 2006 (11) 